\title{
Human preferences for species conservation: Animal charisma trumps endangered status
}

\author{
Agathe COLLEONY*1 \\ Susan CLAYTON ${ }^{2}$ \\ Denis COUVET ${ }^{1}$ \\ Michel SAINT JALME ${ }^{1}$ \\ Anne-Caroline PREVOT ${ }^{1}$
}

${ }^{1}$ Centre d'Ecologie et des Sciences de la Conservation (CESCO UMR7204), Sorbonne Universités, MNHN, CNRS, UPMC, CP51, 57 rue Cuvier, 75005 Paris, France

2Department of Psychology, College of Wooster, 1189 Beall Avenue, Wooster, OH 44691, United States

*Corresponding author: agathe.colleony@gmail.com; Phone: +33140793557

This manuscript has been published in Biological Conservation, and should be cited as follow:

Colléony, A., et al., Human preferences for species conservation: Animal charisma trumps endangered status, Biological Conservation (2016), http://dx.doi.org/10.1016/j.biocon.2016.11.035 


\begin{abstract}
A good deal of research has recently focused on people's commitment to biodiversity conservation by investigating their "willingness-to-pay" (WTP). Because of the public's self-reported preferences for species that are more charismatic or similar to humans, conservation programs are often biased toward these species. Our study aimed to explore the determinants of WTP among 10066 participants in a zoo conservation program. The program aims to raise money to support conservation programs and involves donating a sum of money to "adopt" an animal in the zoo. We explored whether participants were influenced by particular scientific characteristics of the animal (IUCN conservation status and phylogenetic distance from humans) or by more affect-related characteristics, such as the charisma of the animal. We found that participants did not choose an animal to adopt because of the endangered status of the species, and did not donate more to endangered species than to other species. Instead, they were more likely to choose a charismatic species. However, surprisingly, those who chose a less charismatic species gave more money on average to the program than those who adopted more charismatic species, suggesting a higher level of commitment among the former. These results therefore suggest that this type of conservation program may not be an effective way of reconnecting people with conservation issues related to endangered species. We therefore advise zoos to communicate more strongly on the level of threat to species and to increase the ratio of endangered over charismatic species in their animal adoption programs.
\end{abstract}

Key words: animal adoption program, charisma, conservation status, phylogenetic distance, willingness-to-pay, zoo.

\title{
Highlights
}

- People did not donate more to the more endangered species in a conservation program

- Charismatic species were more likely to be chosen

- Monetary donations per person were on average higher for less charismatic species

- Participants donated more money to species that are more similar to humans 


\section{Introduction}

The accelerating loss of biodiversity is now widely acknowledged, with a steep increase in the number of species listed as Critically Endangered (e.g. from 168 to 209 mammal species) or Endangered (e.g. from 31 to 810 amphibian species) from 1996 to 2015, according to the International Union for Conservation of Nature Red List of endangered species (IUCN 2015).

Ambitious conservation policies depend on people's concern for biodiversity, which determines their commitment. One way of investigating their concern is to analyze their willingness-to-pay (WTP) (Balmford et al. 2004, Bateman et al. 2013, Togridou et al. 2006, Zheng et al. 2013). Most studies have focused on the value given to ecosystems (Balmford et al. 2004). Among the few studies that have explored the value given to species, all of them, to our knowledge, have relied on participants' self-reported hypothetical species choices or intentions to support a program (Gunnthorsdottir 2001, Tisdell et al. 2006), rather than on their actual behaviour (i.e. real money invested). For instance, based on hypothetical species choices and money allocation, Martín-Lopez et al. (2007) found that affectrelated factors (e.g. charisma) have more influence on WTP than ecological or scientific considerations. They also found that respondents with better knowledge of biodiversity and greater experience with nature were more willing to donate for the conservation of non-charismatic species that were locally endangered (Martín-López et al. 2007). These results needed to be tested in real-life settings, with actual species valuations.

People also seem to have a preference for conserving animals that are similar to humans (DeKay \& McClelland 1996, Gunnthorsdottir 2001, Plous 1993, Samples et al. 1986). The preference among humans for animal species similar to them has been formalized as the Similar Principle Theory (Plous 1993). This theory is supported by the findings of a research team in Australia, which showed that respondents appeared to favour the survival of mammals rather than birds or reptiles (Tisdell et al. 2006). Another study in the United States showed that physical characteristics (e.g. physical length) were better predictors of government spending decisions for conserving endangered species than more scientific characteristics, such as the level of threat or taxonomic distinctiveness (Metrick \& Weitzman 1996). This prompts the hypothesis that the chances of survival for many species depend as much on human preferences as on more biological requirements (e.g. minimum population size).

In this study, we wanted to investigate WTP and its determinants more closely at the individual level, in a situation where money for species conservation is actually given. Among the numerous existing conservation programs, zoological institutions have been involved in both ex-situ (e.g. captive breeding) and in-situ programs (e.g. significant financial contributions to field conservation projects) (Gusset \& Dick 2011). However, the way zoos contribute to conservation is still controversial: for instance, zoos mostly display large-bodied vertebrates and less-threatened species (Balmford et al. 1995, Conde et al. 2011, Fa et al. 2014, Martin et al. 2014). One reason for such bias toward large vertebrates is the general public preference for large mammals and rare or charismatic species in zoos (Angulo et al. 2009, Ward et al. 1998). However, endangered species may not be charismatic, and vice versa, so that the relationship between zoo exhibits and biodiversity preservation can be complex. In any case, more information is needed on public preferences in zoos, and how zoos could integrate such preferences to connect the public with biodiversity preservation.

To support in-situ conservation programs, zoos have developed different strategies to raise money. One of them is the worldwide strategy of "Animal adoption" programs: people can donate a certain amount of money to the zoo; in return, they receive various benefits (e.g. the zoo's newsletter, meeting zoo keepers, free entrance tickets). In France, participants of such programs are named "godfathers/mothers" of the animal(s) they chose, whereas they are mostly called "parents" in English speaking countries (e.g. United States). Although there are obviously cultural differences regarding this aspect, we will refer here to participants as "parents", to adopt a more neutral position. Such programs foster a more intimate and privileged relationship between participants and a particular

To cite this manuscript: Colléony, A., et al., Human preferences for species conservation: Animal charisma trumps endangered status, Biological Conservation (2016), http://dx.doi.org/10.1016/j.biocon.2016.11.035 
animal, via its adoptive status, compared to non-participants who visit the zoo. However, emotional responses to animals vary widely between and within taxonomic groups (Myers et al. 2004). For instance, primates are more likely to elicit positive emotional responses, because of their close similarities with humans (Plous 1993); conversely, invertebrates are expected to elicit more fearful or aversive emotional responses (Kellert 1993).

Our study therefore aimed to explore people's willingness-to-pay for species conservation through their actual donations to a zoo animal adoption program, by (1) clarifying whether people consider biological characteristics (e.g. threat level, phylogenetic distance from humans), more affect-related ones (e.g. level of charisma) or the combination of such characteristics in their choice of animal and their willingness-to-pay; (2) assessing whether attitudes toward animals (e.g. emotional responses) are reflected in participants' support for their conservation; (3) exploring the impact of the donor's relationship with nature on their choice of an animal and amount of money donated to the program. We assessed these relationships by exploring individual connectedness with nature (Inclusion of Nature in Self, see Schultz 2001) and childhood experiences of nature (Chawla 2007) according to how far they spent their childhood in a rural setting.

We are not aware of any previously published research on animal adoption in zoos, despite the relevance of such programs to species conservation. This study therefore makes an important contribution to zoo conservation programs, and will help to clarify the effectiveness of zoo conservation programs in both raising money for field conservation projects and reconnecting people with conservation issues related to endangered species.

Based on previous research findings, we hypothesized (1) that the level of threat and the phylogenetic distance from humans, but also less scientific considerations (e.g. whether the species is charismatic or not) are significant factors in determining the choice of an animal and the amount donated per participant, with larger donations expected for species that are more threatened, more similar to humans and more charismatic; to better understand the impact of the animals' characteristics, we also looked for interactions among them: for example, perhaps charisma only matters when species are not endangered, and perhaps it is sufficient for an animal to be either phylogenetically close to humans or charismatic. We also hypothesized (2) that attitudes toward animals (i.e. emotional responses) reflect the support of participants for their conservation; (3) that a stronger sense of connection with nature and more experience of nature during childhood influence respondents' choices of animal towards species that are less charismatic and less similar to humans.

\section{Materials and Methods}

\subsection{Animal Adoption program}

The Paris Zoological Park (PZP) opened in 1934, but closed in 2008 for renovation. It reopened in April 2014, as an "immersive" zoo: the 15 ha Park is now divided into five different biozones, where the enclosures are designed to immerse the visitor in the animal's natural environment. Physical barriers were, as far as possible, either removed or kept out of sight (e.g. glass instead of fences).

In late 2013, the PZP set up an animal adoption program allowing members of the public to adopt one or more animals living in the zoo, for conservation purposes. A list of 29 different named individual animals was proposed (see table 1), and adopters were free to donate as much money as they wanted. However, six amounts ranging from $15 €$ to $1000 €$ were proposed as guidelines, with a sliding scale of benefits offered to the adopter in return. The money donated to the program can be deducted from income tax at a rate of $66 \%$ of the amount. The adoption lasts for one year, starting from the day of adoption. 
Table 1: List of animals available for adoption, with given name, scientific name, taxonomic group, total number of adoptions and amount of money raised per animal (in Euros). The animals are shown in decreasing order of total adoptions.

\begin{tabular}{|c|c|c|c|}
\hline $\begin{array}{l}\text { Taxonomic } \\
\text { group }\end{array}$ & Name, animal (scientific name) & $\begin{array}{c}\text { Total } \\
\text { number of } \\
\text { adoptions }\end{array}$ & $\begin{array}{c}\text { Amount of } \\
\text { money raised for } \\
\text { each animal }(€)\end{array}$ \\
\hline Mammal & Aramis, a jaguar (Panthera onca) & 1479 & 89152 \\
\hline Mammal & $\begin{array}{l}\text { Adeline, a West African giraffe (Giraffa } \\
\text { camelopardalis) }\end{array}$ & 1463 & 73550 \\
\hline Mammal & Lena, a Scandinavian lynx (Lynx lynx) & 999 & 62935 \\
\hline Mammal & Diablo, the Spanish wolf (Canis lupus signatus) & 822 & 41466 \\
\hline Mammal & Nero, an African lion (Panthera leo) & 785 & 40640 \\
\hline Mammal & Diego, a European otter (Lutra lutra) & 688 & 37410 \\
\hline Mammal & Tinus, a manatee (Trichechus manatus) & 466 & 28065 \\
\hline Bird & $\begin{array}{l}\text { Indigo, a hyacinth macaw (Anodorhynchus } \\
\text { hyacinthinus) }\end{array}$ & 367 & 18310 \\
\hline Mammal & Patagonian puma (unnamed) (Puma concolor) & 349 & 18510 \\
\hline Mammal & Azufel, a greater bamboo lemur (Prolemur simus) & 345 & 24005 \\
\hline Mammal & Efatra, a crowned sifaka (Propithecus coronatus) & 331 & 22096 \\
\hline Mammal & Serdtse, a Grévy's zebra (Equus grevyi) & 312 & 13670 \\
\hline Mammal & Zakko, a wolverine (Gulo gulo) & 279 & 16305 \\
\hline Mammal & Wami, a white rhinoceros (Ceratotherium simum) & 269 & 19195 \\
\hline Bird & $\begin{array}{l}\text { Pigloo, a Humboldt penguin (Spheniscus } \\
\text { humboldti) }\end{array}$ & 259 & 15306 \\
\hline Mammal & $\begin{array}{l}\text { Luca, a common woolly monkey (Lagothrix } \\
\text { lagotricha) }\end{array}$ & 235 & 12430 \\
\hline Mammal & Mojo, a southern pudu (Pudu puda) & 206 & 11060 \\
\hline Amphibian & Tana, a false tomato frog (Dyscophus guineti) & 185 & 7969 \\
\hline Mammal & $\begin{array}{l}\text { Tabitha, a giant anteater (Myrmecophaga } \\
\text { tridactyla) }\end{array}$ & 148 & 9185 \\
\hline Mammal & Uyuni, a Guinea baboon (Papio papio) & 138 & 8978 \\
\hline Mammal & Zoe, a greater kudu (Tragelaphus strepsiceros) & 120 & 5217 \\
\hline Mammal & Quida, a lowland tapir (Tapirus terrestris) & 113 & 6555 \\
\hline Reptile & $\begin{array}{l}\text { Gertrude, a European pond turtle (Emys orbicularis } \\
\text { orbicularis) }\end{array}$ & 110 & 8622 \\
\hline Mammal & $\begin{array}{l}\text { Portos, a South American sea lion (Otaria } \\
\text { flavescens) }\end{array}$ & 106 & 5006 \\
\hline Arthropod & $\begin{array}{l}\text { Tegu, a curly haired tarantula (Brachypelma } \\
\text { albopilosum) }\end{array}$ & 94 & 3746 \\
\hline Reptile & $\begin{array}{l}\text { Mandi, a Madagascar tree boa (Sanzinia } \\
\text { madagascariensis) }\end{array}$ & 91 & 3387 \\
\hline Reptile & Leon, a panther chameleon (Furcifer pardalis) & 84 & 3310 \\
\hline Bird & Satory, a griffon vulture (Gyps fulvus) & 60 & 5041 \\
\hline Fish & Zyko, an arapaima (Arapaima gigas) & 26 & 1900 \\
\hline
\end{tabular}

Overall, the raw data from the program we had access to included the following variables for each adoption between December 2013 and February 2015: animal chosen, amount of money donated, participant's zip code, age, and the date of adoption. Because the program is explicitly presented as supporting in-situ conservation programs, we used the amount of money donated per person for a particular animal as a measure of their willingness-to-pay for the conservation of this species. These raw data represent 10066 participants in the adoption program.

To cite this manuscript: Colléony, A., et al., Human preferences for species conservation: Animal charisma trumps endangered status, Biological Conservation (2016), http://dx.doi.org/10.1016/j.biocon.2016.11.035 
Secondly, we sent an email to all the program participants to invite them to fill in an online questionnaire, in French, about their experience with the program. We collected data for 6 months (February - September 2015), and received 2134 completed questionnaires, which represents a $21.20 \%$ rate of participation in our survey.

\subsection{Survey instrument}

In the survey questionnaire, we investigated the components of the adoption, whether the participants visited the chosen animal in the zoo, the emotions they felt towards this animal in the zoo, and personal information on their relationships with nature (connectedness with nature, concern for biodiversity and how far they spent their childhood in a rural setting), their age and gender.

\subsection{Components of the adoption}

We asked the participants whether they adopted the animal for themselves, for someone else or if they had received it as a gift. We recorded the number of adoptions and animal(s) each participant adopted, as well as the amount of money donated per animal. Finally, we asked the participant to rank nine different possible motivations for the adoption, from 1 - least important reason, to 9 -most important reason. The following nine reasons were listed in random order : "to support the zoo's conservation mission", "to support the zoo's research mission", "for the benefits", "for tax relief", "because I feel a connection with this animal", "because I like the Paris zoo", "to contribute to the renovation of the zoo", "to raise someone's awareness", "because the species is endangered".

\subsection{Visits to the adopted animal and emotions felt}

Participants were asked whether they had visited the zoo since the renovation, and whether they had had a chance to observe their chosen animal. For those who visited the zoo and met the adopted animal, we asked to what extent they felt each of a list of five positive emotions (Interest, Fascination, Pleasure, Pride and Joy) and five negative ones (Fear, Sadness, Anger, Worry and Shame), from 1-not at all, to 5-very much. We restricted the question related to emotions to those who had had a chance to observe the animal because we were interested in their emotional reaction to the animal in the zoo, rather than in their beliefs and emotional reactions towards the species in general. Positive and negative emotions were mixed and presented randomly for each participant.

\subsection{Personal information}

We used an adapted version of the Inclusion of Other in the Self (IOS) scale (Aron et al. 1992) to measure individual beliefs about how interconnected people feel with the natural world, via a series of overlapping circles labelled "nature" and "self" (Inclusion of Nature in Self scale, see Schultz 2001).

Participants were also asked to what extent they were worried about biodiversity, from 1-not at all, to 5-very much. We asked whether they spent their childhood in a rural or urban setting, from 1-very urbanized, to 5-very rural. Finally, we asked for the gender and provided six age categories (18-30, 31$40,41-50,51-60,61-70$ and over 70), which we recoded into a numerical scale of 1 to 6 .

\subsection{Biological and non-biological characteristics of the animals}

We assessed two biological characteristics of the animals, as follows: (1) the level of threat to the species, according to the International Union for Conservation of Nature (IUCN) Red List, which we coded from 1 for least concern (LC), to 5 for critically endangered (CR) (IUCN 2015); (2) the phylogenetic distance from humans, obtained from http://tolweb.org/tree, which we coded from 1 for closest to humans (e.g. primates) to 9 for the more distant species (e.g. tarantula). This coding reflected the respective ranks of the species considered in relation to humans, rather than their theoretical phylogenetic distance from humans. In other words, the closest species to humans, i.e. nonhuman primates, were coded 1 , the second closest species to humans, i.e. carnivores, were coded 2 , and so on, until the most distant species to humans, i.e. invertebrates, were coded 9. 
In addition, we attributed two characteristic non-biological traits to each animal species. The first was the charisma of the species, which we identified by averaging the number of Google ${ }^{\mathrm{TM}}$ searches (in France only) from January to December 2014. Charisma has been defined as "a special magnetic charm or appeal" in the Merriam-Webster dictionary (www.merriam-webster.com). Although charisma is a complex notion, difficult to be estimated, Google ${ }^{\mathrm{TM}}$ searches were used as a proxy for animal charisma, as it reflects people's interest for the species. We examined such searches over a year, a sufficiently large period to avoid that particular events - like a media controversy about an animal death in a zoo - significantly influence our estimate. A similar approach has already been used, with newspaper (two-month search period) reports as a proxy for the level of awareness of the public (Duarte et al. 2008). The second was the alphabetical order of the name given to the animals, from 1 for A (e.g. Aramis the jaguar) to 26 for Z (e.g. Zyko the arapaima), because the program's website lists the names of the 29 animals in alphabetical order. We ascertained from zoo staff that the animals were not named with any reference to the alphabetical order.

\subsection{Statistical analysis}

All the analyses were performed using R 3.0.2 ( $\mathrm{R}$ Core Team 2013). Response variables were log-transformed to make data conform to normality.

\subsubsection{Effect of biological and non-biological characteristics of the animal on adoption choices,} amounts of money donated and emotions felt for the animal

We found no significant correlation between the four characteristics of the animal considered (i.e. IUCN threat level, phylogenetic distance from humans, charisma according to Google ${ }^{\mathrm{TM}}$ searches and alphabetical order of the name), using Pearson's correlation tests (coefficients ranging from -0.33 to 0.32 ).

From the complete data set from the program, we then modelled the determinants of animal choice using linear regression. We assessed the number of adopters (ADP) for each of the 29 animal species studied as the response variable, and the IUCN threat level (THR), phylogenetic distance from humans (PHY), "Google ${ }^{\mathrm{TM} "}$ charisma (CHA), alphabetical order of the name (ALP) and CHA-PHY, CHATHR and THR-PHY interactions as independent variables. We then applied a stepwise model selection based on Akaike Information Criterion (AIC) scores to select the best model.

We used the same stepwise model selection methodology to build up a second model to analyze the determinants of the amount of money donated. Here, we assessed the amount of money donated per person (INV) as the response variable and the same biological and non-biological variables (i.e. THR, PHY, CHA, ALP and CHA-PHY, CHA-THR and THR-PHY interactions) as independent variables. For this analysis, we selected only the participants who had adopted a single animal ( $N=9$ 669), to avoid any bias due to multiple adoptions by a single participant.

Finally, using the questionnaire data, we modelled the determinants of both positive and negative emotions toward the adopted animal using linear mixed-effects models. First, we assessed the average score of positive emotions felt for the animal as the response variable, the same four variables (i.e. THR, PHY, CHA and ALP) as independent variables, and the participant as a random effect to control for multiple adoptions by a single person. The same model was run with the average score of negative emotions felt for the animal as the response variable. For these two models, we only considered those who had adopted an animal for themselves, because we were interested in personal involvement in the adoption. Data on emotional scores were available for 511 people who adopted an animal for themselves. We used the 'nlme' 3.1-125 package (Pinheiro \& Bates 2016).

To cite this manuscript: Colléony, A., et al., Human preferences for species conservation: Animal charisma trumps endangered status, Biological Conservation (2016), http://dx.doi.org/10.1016/j.biocon.2016.11.035 


\subsubsection{Effect of background variables on animal choice and amount of money donated in relation to biological and non-biological characteristics}

Using the questionnaire data, we explored whether connectedness with nature, concern for biodiversity, a rural setting during childhood, gender and age had an effect on animal choice, in relation to phylogenetic distance from humans, IUCN threat level and "Google ${ }^{\mathrm{TM}}$ " charisma. To do so, we used a linear mixed-effect model with phylogenetic distance from humans as the response variable and connectedness with nature, rural setting during childhood, concern for biodiversity, gender and age as independent variables. We applied a random effect to the participant variable. We performed

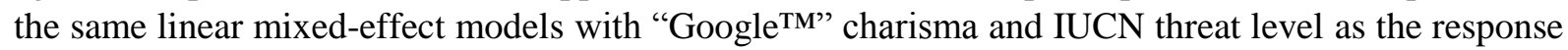
variables.

Additionally, we explored whether connectedness with nature, concern for biodiversity, a rural setting during childhood, gender and age had an effect on the amount of money donated, by performing the same linear mixed effect model with amount of money donated as the response variable.

\section{Results}

\subsection{Participant profiles}

Altogether, 10066 different people took part in the program, adopting one or several animals (619 persons adopted more than one animal, usually two), resulting in a total of 10929 adoptions by the end of February 2015. Most of the participants (99\%) were living in France. 30\% were from Paris, and $16.7 \%$ of these were living in the $12^{\text {th }}$ arrondissement in Paris (i.e. where the zoo is located). Given that in France in 2013, Parisians represented 3.43\% of the French population, and people living in the $12^{\text {th }}$ arrondissement in Paris represented $6.49 \%$ of Parisians (INSEE 2013), the proportion of Parisians and $12^{\text {th }}$ arrondissement inhabitants in our sample was relatively large compared to the population in France.

A total of $613021.36 €$ had been collected by the end of February 2015, and most participants donated between 30 and $74 €$ (a minimum donation of $30 €$ was necessary to receive the program benefits) (Fig. $1)$.

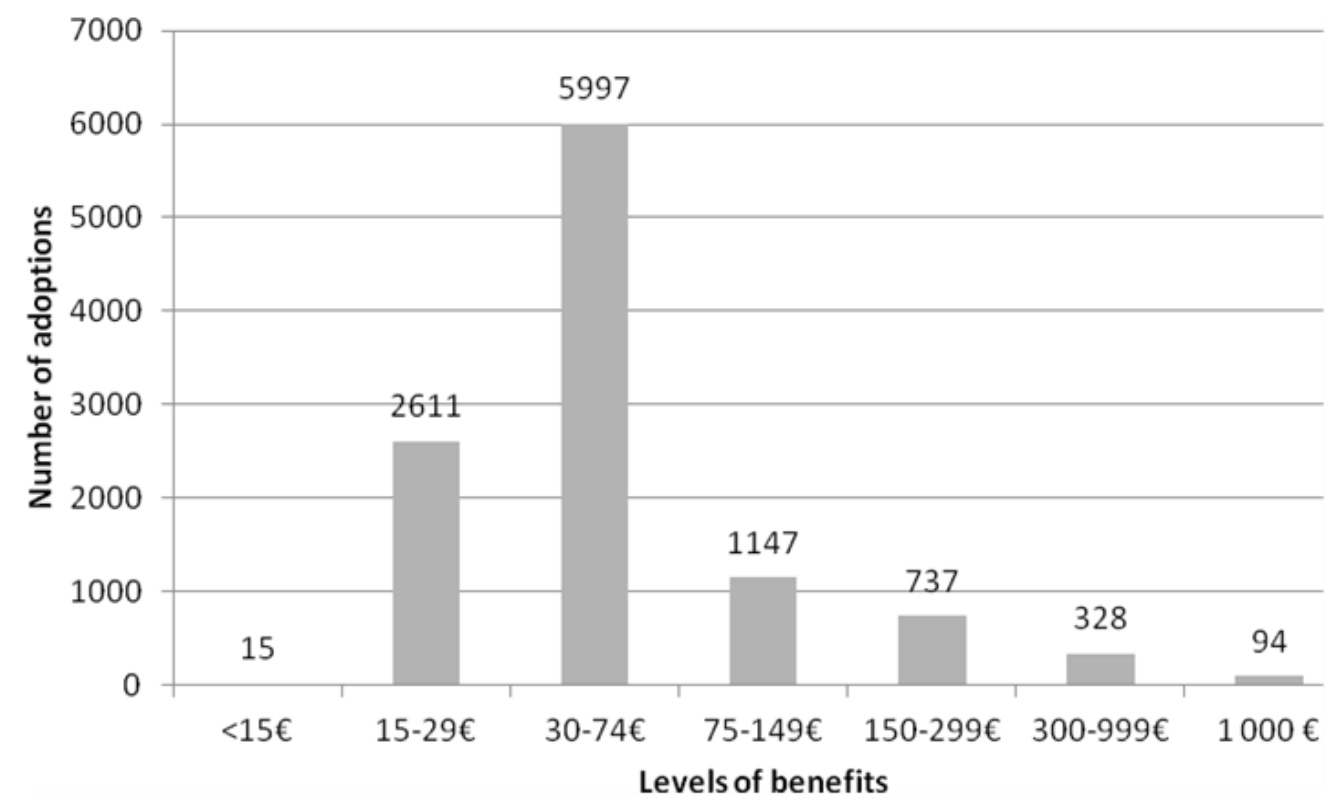

Figure 1: Numbers of adoptions for each level of benefits offered by the program. Below $15 €$, the participant did not receive any benefit in return for participating.

To cite this manuscript: Colléony, A., et al., Human preferences for species conservation: Animal charisma trumps endangered status, Biological Conservation (2016), http://dx.doi.org/10.1016/j.biocon.2016.11.035 
Among the 2134 respondents to our questionnaire, 868 had adopted an animal for themselves, 826 as a gift to someone else, and 243 had received the adoption as a gift. The remaining 141 respondents were participants who combined some of the previous three types of adoption. 1313 respondents had visited the zoo since it reopened (61.5\%) and 1533 had visited the zoo before its renovation $(71.8 \%)$. 1254 owned a pet $(58.8 \%)$, which is similar to the proportion for the French population as a whole (FACCO/TNS SOFRES 2015). 784 respondents were involved in environmental or animal protection organizations $(36.7 \%)$, which is a much higher proportion than for the French population as a whole (11\%) (European Commission 2013).

Based on the three most important reasons cited for participating, respondents mostly adopted an animal for themselves or as a gift to support the zoo's conservation mission (25.09\%), to support the zoo's research mission (15.45\%), because they felt a connection with the animal they chose $(12.66 \%)$, to contribute to the zoo's renovation (12.22\%) and because the species they chose is endangered (11.43\%). The remaining four reasons - because they like the zoo, to sensitize someone, for the benefits and for tax relief - accounted for $9.89 \%, 9.12 \%, 2.42 \%$ and $1.73 \%$ respectively.

\subsection{Effect of biological and non-biological characteristics of the animal on the adoption choice, amount of money donated and emotions felt for the animal}

\subsubsection{Number of adopters per animal}

All interactions were removed during stepwise model selection process. According to the best model (R-squared value $=0.54)$, number of adopters per animal was positively associated with level of "Google ${ }^{\mathrm{TM}}$ " charisma, and negatively associated with alphabetical order (Table 2). These results suggest that the more charismatic the species was, the more it was chosen by participants, and that participants were more likely to choose an animal whose name started with a letter near the top of the alphabet than further down in the alphabet, i.e., at the top of the website page, which gives the names of the animals in alphabetical order. At the opposite, we found no significant relationship between number of adopters per animal and IUCN threat level and phylogenetic distance to humans, suggesting that neither the IUCN threat level nor the phylogenetic distance to humans had any effect on the number of adopters per animal.

Table 2: Results of linear regression analyses that included five independent variables to explain animal choice (through number of adopters per animal) and amount of money donated. Estimates \pm standard errors and level of significance $(* \mathrm{p}<0.05 ; * * \mathrm{p}<0.01 ; * * * \mathrm{p}<0.001)$ are given, for the best model retained using stepwise model selection based on Akaike Information Criterion.

\begin{tabular}{|c|c|c|}
\hline Independent variables & Number of adopters per animal & $\begin{array}{l}\text { Amount of money donated per } \\
\text { animal }\end{array}$ \\
\hline "Google & $0.367 \pm 0.146 *$ & $-0.043 \pm 0.016 * *$ \\
\hline IUCN threat level (THR) & $0.090 \pm 0.144$ & $0.004 \pm 0.009$ \\
\hline $\begin{array}{l}\text { Phylogenetic distance to humans } \\
\text { (PHY) }\end{array}$ & $-0.223 \pm 0.156$ & $-0.051 \pm 0.017 * *$ \\
\hline Alphabetical order (ALP) & $-0.314 \pm 0.140 *$ & $-0.020 \pm 0.009 *$ \\
\hline Interaction between $\mathrm{CHA}$ and $\mathrm{PHY}$ & $\begin{array}{c}\text { Removed during stepwise model } \\
\text { selection }\end{array}$ & $-0.045 \pm 0.021 *$ \\
\hline Interaction between CHA and THR & $\begin{array}{c}\text { Removed during stepwise model } \\
\text { selection }\end{array}$ & $\begin{array}{c}\text { Removed during stepwise model } \\
\text { selection }\end{array}$ \\
\hline Interaction between THR and PHY & $\begin{array}{c}\text { Removed during stepwise model } \\
\text { selection }\end{array}$ & $\begin{array}{c}\text { Removed during stepwise model } \\
\text { selection }\end{array}$ \\
\hline
\end{tabular}

Although the relationship with phylogenetic distance to humans was not significant, removing this variable from the model did not change the AIC; because it was a variable of interest, we decided to keep this variable in the final model. Although the relationship with IUCN threat level was not significant either, removing this variable from the model increased the AIC score (from 59.54 to 62.88), but decreased the p-value associated.

To cite this manuscript: Colléony, A., et al., Human preferences for species conservation: Animal charisma trumps endangered status, Biological Conservation (2016), http://dx.doi.org/10.1016/j.biocon.2016.11.035 


\subsubsection{Amount of money donated per animal}

The best model from the stepwise model selection explained a very low amount of the total variance (R-squared value $=0.002$ ), but it was better in terms of AIC that the null-model. According to this selected model, amount of money donated per animal was negatively associated with "Google" charisma, phylogenetic distance to humans and alphabetical order (Table 2). These results suggest that the more charismatic the species, the smaller the amount of money donated; the smaller the phylogenetic distance from humans, the greater the amount of money donated; and the participants were also more likely to give more money to animals whose name started with a letter near the top of the alphabet (i.e. first presented in the website) than further down in the alphabet. In addition, the interaction between "Google" $\mathrm{TM}^{\mathrm{TM}}$ charisma and phylogenetic distance to humans was negatively associated with amount of money donated per animal (Table 2), suggesting that for more charismatic species, phylogenetic distance to humans had a stronger negative effect on amount of money donated. Other interactions were not significant. Finally, we found no significant relationship with IUCN threat level (Table 2).

\subsubsection{Emotions felt per animal}

These analyses were limited to respondents who had visited the zoo since the renovation and had seen the animal they adopted for themselves or for others (i.e. 511 people).

We found that the IUCN threat level was negatively correlated with positive emotions felt for the animal $(\beta=-0.04, S E=0.01, p=0.008)$, and positively correlated with negative emotions felt for the animal $(\beta=0.04, S E=0.01, \mathrm{p}=0.015)$. No correlation was observed between other variables (phylogenetic distance from humans and alphabetical order) and either positive or negative emotions felt for the animals. Interactions were not significant in the models. These results suggest that IUCN threat level had a significant effect in determining the emotions felt for the animal, lowering positive emotions and strengthening negative emotions.

\subsection{Effect of background personal characteristics on animal choice and amount of money donated in relation to its biological and non-biological characteristics}

We found no effect of connectedness with nature on participants' choices in favour of charismatic, phylogenetically distant or more endangered species (Table 3). Similarly, choice of charismatic, phylogenetically distant or more endangered species was not related to respondents' age, and concern for biodiversity (Table 3). A more rural childhood was negatively correlated with the charisma of animals adopted, and positively correlated with their phylogenetic distance from humans (Table 3). These results suggest that participants who spent their childhood in a rural setting were more likely to choose species that are less charismatic and phylogenetically more distant from humans.

Additionally, we found no significant relationship between the amount of money donated and any of the demographic and background variables (Table 3). 
Table 3: Results of linear mixed-effect models that included five independent variables to explain animal choice (through "Google ${ }^{\mathrm{TM}}$ " charisma, phylogenetic distance to humans and IUCN threat level) and amount of money donated. Estimates \pm standard errors and level of significance $(* p<0.05 ; * *$ $\mathrm{p}<0.01 ; * * * \mathrm{p}<0.001)$ are given.

\begin{tabular}{|l|c|c|c|c|}
\hline $\begin{array}{l}\text { Independent } \\
\text { variables }\end{array}$ & $\begin{array}{c}\text { "GoogleTM" } \\
\text { charisma }\end{array}$ & $\begin{array}{c}\text { Phylogenetic } \\
\text { distance to humans }\end{array}$ & IUCN threat level & $\begin{array}{c}\text { Amount of money } \\
\text { donated }\end{array}$ \\
\hline $\begin{array}{l}\text { Connectedness with } \\
\text { nature }\end{array}$ & $0.033 \pm 0.034$ & $-0.001 \pm 0.035$ & $-0.001 \pm 0.036$ & $-0.051 \pm 0.326$ \\
\hline $\begin{array}{l}\text { Rural setting during } \\
\text { childhood }\end{array}$ & $-0.082 \pm 0.036^{*}$ & $0.086 \pm 0.037 *$ & $0.001 \pm 0.037$ & $-0.336 \pm 0.334$ \\
\hline $\begin{array}{l}\text { Concern for } \\
\text { biodiversity }\end{array}$ & $-0.040 \pm 0.034$ & $0.001 \pm 0.036$ & $-0.001 \pm 0.036$ & $0.198 \pm 0.341$ \\
\hline Age & $0.054 \pm 0.032$ & $0.027 \pm 0.033$ & $-0.055 \pm 0.033$ & $0.391 \pm 0.307$ \\
\hline Gender & $-0.080 \pm 0.073$ & $0.138 \pm 0.075$ & $0.021 \pm 0.075$ & $0.221 \pm 0.683$ \\
\hline
\end{tabular}

\section{Discussion}

The results of this study confirm some of our working hypotheses, but surprisingly did not support others, particularly in relation to the charisma and endangered status of the species that participants chose to support. This study also suggests that individual relationships with nature tend to gear people's support of conservation towards species that are less charismatic and less similar to humans. We discuss these results below.

\subsection{Technical effects}

Surprisingly, we found that the alphabetical order of the names given to animals had a strong effect on animal choice. However, charismatic species were not significantly high in the alphabetical order. Because animals were listed by name in alphabetical order on the adoption program's website, this result therefore suggests that many participants may have selected the first available animals on the website page. Our interpretation is that the alphabetical order effect shows that people are not willing to spend much time on choosing the species they wish to support, but go for the first animal displayed once they have decided to support a conservation program. Does this indicate a lack of interest, or a feeling of ignorance? Further studies are needed to clarify this point.

\subsection{Similarity effect}

As expected, similarity to humans was found to influence WTP for species conservation: participants were more likely to donate more on average for species that are phylogenetically closer to humans. This result is consistent with previous research giving credit to the Similarity Principle in conservation support (DeKay \& McClelland 1996, Gunnthorsdottir 2001, Plous 1993, Samples et al. 1986).

\subsection{Charisma effects}

Our major result revealed complex effects of animal charisma on support for conservation. We showed first that the level of charisma had a positive impact on animal choice, but a negative impact on the amount donated, or WTP. The positive effect of charisma on animal choice is consistent with previous literature (Bennett et al. 2015, Skibins et al. 2013); however, its negative effect on WTP is striking, and suggests that those who adopted less charismatic species probably engage more strongly with species conservation, acknowledging the strong selection biases that might exist in favour of charismatic species. In other words, committed people might tend to make a strategic choice, anticipating that some non-charismatic species are likely to attract little support and deciding to compensate accordingly. Indeed, since we found that concern for biodiversity was not related to choice of charismatic species, it seems doubtful that a higher WTP among people who adopted noncharismatic species could be due to them having stronger pro-conservation attitudes.

To cite this manuscript: Colléony, A., et al., Human preferences for species conservation: Animal charisma trumps endangered status, Biological Conservation (2016), http://dx.doi.org/10.1016/j.biocon.2016.11.035 
Additionally, we found that when "GoogleTM" level of charisma increased, the negative effect of phylogenetic distance to humans on amount of money donated increased, suggesting that participants who adopted less charismatic species cared less about phylogenetic distance to humans, compared to those who adopted more charismatic species.

\subsection{Effects of species conservation status}

Another unexpected result is the lack of any effect of the species conservation status on animals chosen and amounts donated. This indicates that people taking part in a program presented as dedicated to species conservation do not consider endangered status criteria when choosing an animal to adopt and deciding on the amount they wish to donate. This was even more surprising given the high proportion of participants who reported being involved in organizations for environmental and animal protection.

On the other hand, we found that the conservation status of the animal had a significant effect in determining emotional responses towards it. Compared to other respondents, people who adopted more threatened species were more likely to express negative emotions, and the animals they adopted were less likely to elicit positive emotions than the less threatened species. Linking this to the result on willingness-to-pay suggests that emotional responses towards animals did not reflect participants' willingness-to-pay for species conservation.

A potential limitation of this result is that we were unsure whether the participant visited the animal after the adoption process, or whether the visit to the animal elicited the desire to adopt it. Nevertheless, all species are displayed similarly in the zoo, regardless of how endangered they are. Information on conservation status is equally available for all the species (e.g. on the program website and on the species information panels in the zoo). Finally, the more threatened species available for adoption belonged to different taxonomic groups, with primates, which are usually more positively perceived by visitors because of their similarities to humans (Plous 1993), particularly well represented. We are also aware that although those who responded to the questionnaire were relatively similar in age to the program participants as a whole, those who did not complete the questionnaire survey might have had different attitudes towards the animals. The variance in the response variables explained by our models was relatively low, which means that a large part of the variance is not accounted by our models, and that other factors than chance might matter, e.g. socio-economic variables. Notably, although we did not find a significant relationship between demographic variables and amount of money donated, personal income, not available in our dataset, may explain the amount of money donated. Finally, the species that could be adopted were selected by the program managers and the list of species (Table 1) was therefore imposed to this study. Biases, especially toward mammal species, should therefore be mentioned as potential limitations for these results, and further research would be necessary to confirm our results.

\subsection{Effects of participants' personal characteristics}

As expected, our results suggest that childhood experiences of nature have a strong influence on the choice of animals, with people with more rural experiences during childhood choosing species that are less charismatic and less similar to humans. Indeed, childhood experiences of nature have been found to have a profound effect on the way people experience nature in adulthood (Chawla 2007), and previous research has also noted that experience of nature tends to influence willingness-to-pay for less charismatic species (Martín-López et al. 2007). We did not find any effect of connectedness with nature on the choice of animals to adopt, although it has been suggested that this is associated with childhood experiences of nature (Chawla 2007). This could be explained by the fact that we assessed connectedness with nature through a single question, and relied on self-reporting by participants of a conscious personal relationship with nature. 


\section{Conclusion}

Overall, our survey based on actual monetary donations produced results similar to those from a previous survey based on hypothetical animal choices and willingness-to-pay for species conservation (Martín-López et al. 2007). Our study also indicates that people's choices of animals to adopt and their willingness-to-pay were mostly driven by affect-related motivations and arbitrary influences, rather than by more ecological considerations such as the endangered status of a species. We therefore suggest that people participating in such conservation programs mostly look for the intimate relationships they allow with individual animals.

Our work has several implications for zoo strategies concerning adoption programs for conservation, regarding the selection of animals proposed for adoption: similarity with humans matters, especially for more charismatic species, but endangered status is a minor concern; with regard to species charisma, zoos could develop a more strategic targeting approach: either favour charismatic species to recruit higher numbers of participants, or favour non-charismatic species to raise higher individual donations from committed people. Zoos might therefore consider developing a discourse on the importance of species in ecosystem functioning or on adaptation to global change, which is an important way of reconnecting people with biodiversity. Finally, zoos should be aware of the importance of certain choices made (especially regarding the alphabetical order used to present their animals) in presenting their strategic objectives. To prevent low-information visitors or visitors who are already informed but with no real preference among species from choosing the first few proposed animals, we suggest zoos to give participants an additional choice to donating to a general conservation cause or to a fund that allows the zoo to distribute the donations to the program of their choice. However, such solution might look as patronizing, suggesting that experts know better than the public what the choice in regards to nature should be.

Finally, the consequences of our results for the conservation policies of zoos are complex, because the effectiveness of adoption programs as a way of raising conservation awareness remains uncertain. We strongly advise managers of species conservation program to provide potential participants with more in-depth information about levels of threat to species, and perhaps to considerably increase the proportion of more threatened and less charismatic species in their selection of animals for adoption programs. The question certainly arises as to whether a large amount of small donations for charismatic species would be more effective than fewer but larger donations for less charismatic species. In parallel with adoption programs, we recommend more studies on how animal collections could be optimized to maximize ex-situ conservation in zoos, since reconciling conservation with their own financial viability requires zoos to work with both charismatic and non-charismatic threatened species (Delmas 2014). Nevertheless, to raise people's awareness about conservation issues and because of the urgent need to conserve more threatened but less charismatic species, more recommendations are needed on displaying species according to their charisma and conservation status respectively.

Acknowledgements: We wish to thank the managers of the PZP animal adoption program for allowing us to conduct research on the program data, I. Bossanyi for her help, as a professional translator, on improving the English writing style of our manuscript, and the two anonymous reviewers for their comments. Finally, we thank the two anonymous reviewers for providing feedback that greatly improved this manuscript. 


\section{Literature Cited}

Angulo, E., A.-L. Deves, M. Saint Jalmes, and F. Courchamp. 2009. "Fatal Attraction: Rare Species in the Spotlight." Proceedings of the Royal Society B: Biological Sciences 276 (1660): 1331-37. doi:10.1098/rspb.2008.1475.

Aron, Arthur, Elaine N. Aron, and Danny Smollan. 1992. "Inclusion of Other in the Self Scale and the Structure of Interpersonal Closeness." Journal of Personality and Social Psychology 63 (4): 596-612. doi:10.1037/0022-3514.63.4.596.

Balmford, Andrew, Pippa Gravestock, Neal Hockley, Colin J. McClean, and Callum M. Roberts. 2004. "The Worldwide Costs of Marine Protected Areas." Proceedings of the National Academy of Sciences of the United States of America 101 (26): 9694-97. doi:10.1073/pnas.0403239101.

Balmford, Andrew, N. Leader-Williams, and M. J. B. Green. 1995. "Parks or Arks: Where to Conserve Threatened Mammals?" Biodiversity \& Conservation 4 (6): 595-607. doi:10.1007/BF00222516.

Barton, K. 2015. MuMIn: Multi-Model Inference, $R$ Package Version 1.9.13. CRAN. http://CRAN.Rproject.org/package=MuMIn.

Bateman, I. J., A. R. Harwood, G. M. Mace, R. T. Watson, D. J. Abson, B. Andrews, A. Binner, et al. 2013. "Bringing Ecosystem Services into Economic Decision-Making: Land Use in the United Kingdom." Science 341 (6141): 45-50. doi:10.1126/science.1234379.

Bennett, Joseph R., Richard Maloney, and Hugh P. Possingham. 2015. "Biodiversity Gains from Efficient Use of Private Sponsorship for Flagship Species Conservation." Proceedings of the Royal Society of London B: Biological Sciences 282 (1805): 20142693. doi:10.1098/rspb.2014.2693.

Burnham, Kenneth P., David Anderson, and Kathryn P. Huyvaert. 2011. "AIC Model Selection and Multimodel Inference in Behavioral Ecology: Some Background, Observations, and Comparisons." Behavioral Ecology and Sociobiology, no. 65: 23-35.

Chawla, Louise. 2007. "Childhood Experiences Associated with Care for the Natural World." Children, Youth and Environments 17 (4): 144-70.

Conde, A., N. Flesness, F. Colchero, O.R. Jones, and A. Scheuerlein. 2011. "An Emerging Role of Zoos to Conserve Biodiversity." Sciences 331 (6023): 1390-91.

DeKay, Michael L., and Gary H. McClelland. 1996. "Probability and Utility of Endangered Species Preservation Programs." Journal of Experimental Psychology: Applied 2 (1): 60-83. doi:10.1037/1076-898X.2.1.60.

Delmas, Eva. 2014. “Etude Théorique de L'optimisation Des Combinaisons D'espèces Dans Le but de Maximiser La Conservation Ex Situ Dans Les Parcs Zoologiques." Master Environnement de I'Université Paris Sud.

Duarte, Carlos M., William C. Dennison, Robert J. W. Orth, and Tim J. B. Carruthers. 2008. "The Charisma of Coastal Ecosystems: Addressing the Imbalance." Estuaries and Coasts 31 (2): 233-38. doi:10.1007/s12237-008-9038-7.

European Commission. 2013. "Attitudes Towards Biodiversity." Eurobarometer. European Commission.

Fa, J. E., M. Gusset, N. Flesness, and D. A. Conde. 2014. "Zoos Have yet to Unveil Their Full Conservation Potential." Animal Conservation 17 (2): 97-100. doi:10.1111/acv.12115.

FACCO/TNS SOFRES. 2015. "Le Chat Poursuit Sa Progression Au Sein Des Foyers Français." FACCO.

Gunnthorsdottir, Anna. 2001. "Physical Attractiveness of an Animal Species as a Decision Factor for Its Preservation." Anthrozoös 14 (4): 204-15. doi:10.2752/089279301786999355.

Gusset, Markus, and Gerald Dick. 2011. "The Global Reach of Zoos and Aquariums in Visitor Numbers and Conservation Expenditures." Zoo Biology 30 (5): 566-69. doi:10.1002/zoo.20369.

INSEE. 2013. "Institut National de La Statistique et Des Études Économiques: Accueil." http://www.insee.fr/fr/.

IUCN. 2015. “The IUCN Red List of Threatened Species.” http://www.iucnredlist.org/.

To cite this manuscript: Colléony, A., et al., Human preferences for species conservation: Animal charisma trumps endangered status, Biological Conservation (2016), http://dx.doi.org/10.1016/j.biocon.2016.11.035 
Kellert, Stephen R. 1993. "Values and Perceptions of Invertebrates." Conservation Biology 7 (4): 84555. doi:10.1046/j.1523-1739.1993.740845.x.

Martin, T. E., H. Lurbiecki, J. B. Joy, and A. O. Mooers. 2014. "Mammal and Bird Species Held in Zoos Are Less Endemic and Less Threatened than Their Close Relatives Not Held in Zoos." Animal Conservation 17 (2): 89-96. doi:10.1111/acv.12069.

Martín-López, Berta, Carlos Montes, and Javier Benayas. 2007. "The Non-Economic Motives behind the Willingness to Pay for Biodiversity Conservation." Biological Conservation 139 (1-2): 6782. doi:10.1016/j.biocon.2007.06.005.

Metrick, Andrew, and Martin L. Weitzman. 1996. "Patterns of Behavior in Endangered Species Preservation." Land Economics, no. 72: 1-16.

Myers, Olin Eugene, Carol D. Saunders, and Andrej A. Birjulin. 2004. "Emotional Dimensions of Watching Zoo Animals: An Experience Sampling Study Building on Insights from Psychology." Curator: The Museum Journal 47 (3): 299-321.

Pinheiro, José, and Douglas Bates. 2016. Linear and Nonlinear Mixed Effects Models (version 3.1125). https://cran.r-project.org/web/packages/nlme/nlme.pdf.

Plous, S. 1993. "Psychological Mechanisms in the Human Use of Animals." Journal of Social Issues 49 (1): 11-52. doi:10.1111/j.1540-4560.1993.tb00907.x.

R Core Team. 2013. R: A Language and Environment for Statistical Computing. Vienna, Austria: $\mathrm{R}$ Foundation for Statistical Computing.

Samples, Karl C., John A. Dixon, and Marcia M. Gowen. 1986. "Information Disclosure and Endangered Species Valuation." Land Economics 62 (3): 306-12. doi:10.2307/3146394.

Schultz, P. Wesley. 2001. "THE STRUCTURE OF ENVIRONMENTAL CONCERN: CONCERN FOR SELF, OTHER PEOPLE, AND THE BIOSPHERE." Journal of Environmental Psychology 21 (4): 327-39. doi:10.1006/jevp.2001.0227.

Skibins, Jeffrey C., Robert B. Powell, and Jeffrey C. Hallo. 2013. "Charisma and Conservation: Charismatic Megafauna's Influence on Safari and Zoo Tourists' pro-Conservation Behaviors." Biodiversity and Conservation 22 (4): 959-82. doi:10.1007/s10531-013-0462-z.

Tisdell, Clem, Clevo Wilson, and Hemanath Swarna Nantha. 2006. "Public Choice of Species for the 'Ark': Phylogenetic Similarity and Preferred Wildlife Species for Survival." Journal for Nature Conservation 14 (2): 97-105. doi:10.1016/j.jnc.2005.11.001.

Togridou, Anatoli, Tasos Hovardas, and John D. Pantis. 2006. "Determinants of Visitors' Willingness to Pay for the National Marine Park of Zakynthos, Greece." Ecological Economics 60 (1): 308-19. doi:10.1016/j.ecolecon.2005.12.006.

Ward, Paul I., Nicole Mosberger, Claudia Kistler, and Oliver Fischer. 1998. "The Relationship between Popularity and Body Size in Zoo Animals." Conservation Biology 12 (6): 1408-11. doi:10.1111/j.1523-1739.1998.97402.x.

Zheng, H., B. E. Robinson, Y.-C. Liang, S. Polasky, D.-C. Ma, F.-C. Wang, M. Ruckelshaus, Z.-Y. Ouyang, and G. C. Daily. 2013. "Benefits, Costs, and Livelihood Implications of a Regional Payment for Ecosystem Service Program." Proceedings of the National Academy of Sciences 110 (41): 16681-86. doi:10.1073/pnas.1312324110.

To cite this manuscript: Colléony, A., et al., Human preferences for species conservation: Animal charisma trumps endangered status, Biological Conservation (2016), http://dx.doi.org/10.1016/j.biocon.2016.11.035 